\title{
LXIX. The effect of variable specific heat on the discharge of gases through orifices or nozzles
}

\section{William J. Walker Ph.D.}

To cite this article: William J. Walker Ph.D. (1922) LXIX. The effect of variable specific heat on the discharge of gases through orifices or nozzles, Philosophical Magazine Series 6, 43:255, 589-593, DOI: $10.1080 / 14786442208633915$

To link to this article: http://dx.doi.org/10.1080/14786442208633915

曲 Published online: 08 Apr 2009.

Submit your article to this journal $[\pi$

Q View related articles $₫$

4 Citing articles: 3 View citing articles 진 
LXIX. The Effect of Variable Specific Heat on the Discharge of Gases through Orifices or Nozzles. By William J. Walker, Ph.L., University College, Dundee* .

SUMMARY. The following paper raises the question whether or not it is desirable to account for abnormal orifice or nozzle discharges by the consideration of changes in the value of $\gamma$, the index in the equation $p v^{\gamma}=$ constant, for adiabatic changes of state. This appears, generally, to have been the custom hitherto, but, since the actual adiabatic equation under linear variable specific heat conditions is $p v^{m} e^{\lambda \mathrm{T}}=$ constant, the analysis in this paper has been carried out on the latter basis for the purpose of determining, as wearly as possible, what effect such specific heat variation has on discharges. An exact solution does not appear to be derivable, but the method of analysis adopted here may be carried to any degree of accuracy required. The method of analysis is somewhat similar to that adopted in a previous paper dealing with another effect of variable specific heat. The result obtained in the present paper brings out prominently the fact that the error in computing discharges, by the usual constant specific heat theory, increases as the density of the medium in the reservoir is diminished. This fact appears to have been neglected in previous considerations of the subject. It is pointed out, also, that, by means of the discharge formulæ obtained, the method of orifice discharge may be used as a reliable and convenient one for the determination of specific heat variations with temperature.

IN the flow of gases through nozzles and orifices the analysis generally applied to any interpretation of test results is that based on the constancy of the specific heat of the gas concerned. The formulæ derived under such an assumption are, for the velocity of the gas,

$$
u_{c}=\left[2 g \frac{\gamma}{\gamma-1} p_{1} v_{1}\left\{1-x^{\frac{\gamma-1}{\gamma}}\right\}\right]^{\frac{3}{2}} \text { feet per sec., . }
$$

and for the quantity discharged,

$$
\mathrm{Q}_{c}=\mathrm{A}\left[2 g \frac{\gamma}{\gamma-1} v_{1} v_{1}\left(x^{\frac{2}{\gamma}}-x^{\frac{\gamma+1}{\gamma}}\right)\right]^{\frac{1}{2}} \text { lb. per sec., . }
$$

* Communicated by the Author. 
where $p_{1}$ is the pressure in the reservoir in lb. per sq. ft. abs. $v_{1}$ is the specific volume of the gas in the reservoir in cubic feet per $\mathbf{l b}$.,

$$
x=\frac{p}{p_{1}}=\frac{\text { pressure at discharge }}{\text { pressure in reservoir }} \text {. }
$$

The suffix $c$ in $u_{c}$ and $Q_{c}$ refers to the coustancy of specific heat as assumed in the derivation of these formulæ.

In applying the foregoing equations (1) and (2) to experimental results it is customary to account, by one means at least, for departures from theoretical discharges by a suitable variation of $\gamma$. Such a procedure can scarcely be called a satisfactory one, and it is proposed in what follows to deduce a rational formula (assuming, at first, linear variable specific heat conditions) which will require no such adjustment. This can then be extended to include quadratic variable specific heat conditions and so on for any variation of specific heat with temperature of the form $\mathrm{K}=a+b \mathrm{~T}+c \mathrm{~T}^{2}+d \mathrm{~T}^{3}+\ldots$ which may be specified.

In the aliabatic expansion of a gas, the velocity at any cross-section of the stream is given by

$$
u^{2}=2 g \mathrm{~K}_{p} \int_{\mathrm{T}}^{\mathrm{T}_{1}} d \mathrm{~T} \text { fest per sec., . . . }
$$

assuming a reservoir of infinite capacity, $\mathrm{K}_{p}$ being the specific heat at constant pressure, in ft. lb. per lb. per degree centigrade, $\mathrm{T}$ being temperature in degrees centigrade absolute

Let

$$
\begin{aligned}
& \mathrm{K}_{p}=\mathrm{A}+\mathrm{ST}, \\
& \mathrm{K}_{v}=\mathrm{B}+\mathrm{ST},
\end{aligned}
$$

$\mathbf{K}_{v}$ being the specific heat at constant volume.

$$
\begin{aligned}
& \text { Also, let } \quad m=\frac{\mathrm{A}}{\mathrm{B}}, \\
& \text { and } \quad \lambda=\frac{\mathrm{S}}{\mathrm{B}} . \\
& \therefore \quad u^{\grave{2}}=2 g\left[\mathrm{~A}\left\{\mathrm{~T}_{1}-\mathrm{T}\right\}+\frac{\mathrm{S}}{2}\left\{\mathrm{~T}_{1}^{2}-\mathrm{T}^{2}\right\}\right] \\
& =2 g \frac{m}{m-1}\left\{p_{1} v_{1}-p v\right\}\left\{1+\frac{\lambda}{2 m \mathrm{R}}\left(p_{1} v_{1}+p_{2} v_{2}\right)\right\} .
\end{aligned}
$$

Now, during adiabatic changes of state

$$
p v^{m} e^{\lambda T}=\text { constant. }
$$


Variable Specific Heat on Gas Discharges.

$$
\therefore \quad \frac{v}{v_{1}}=\left(\frac{p_{1}}{p}\right)^{\frac{1}{m}}\left\{1+\frac{\lambda}{m \mathrm{R}}\left(p_{1} v_{1}-p v\right)\right\}
$$

to a first appromimation

$$
=\left(\frac{p_{1}}{p}\right)^{\frac{1}{n}} \times f
$$

Equation (4) may therefore be written

$$
\begin{aligned}
& u^{2}=2 g \frac{m}{m-1} p_{1}^{\frac{1}{n}} v_{1}\left\{p_{1} .^{\frac{m-1}{m}}-p^{\frac{m-1}{m}} \times f\right\} \\
& \left\{1+\frac{\lambda p_{1}{ }^{\frac{1}{m}}}{2 m} v_{1}\left(p_{1}^{\frac{m-1}{m}}+p^{\frac{m-1}{m}}\right)\right\} \\
& =2 g \frac{m}{m-1} p_{1} \frac{1}{m} v_{1}\left\{p_{1}^{\frac{m-1}{m}}-p^{\frac{m-1}{m}}-\frac{\lambda p^{\frac{m-1}{m}} p_{1}^{\frac{1}{m}} v_{1}}{m \mathrm{R}}\right. \\
& \left.\left(p_{1}^{\frac{m-1}{m}}-p^{\frac{m-1}{m}}\right)\right\}\left\{1+\frac{\lambda \phi}{m \mathrm{R}}\right\}, \\
& \phi=p_{1}{ }^{\frac{1}{m}} \eta_{1}\left(p_{1} \cdot \frac{m-1}{m}+p^{\frac{m-1}{m}}\right) \text {. } \\
& \because \quad u^{2}=2 g \frac{m}{m-1} p^{p_{1} \frac{1}{m}} v_{1}\left(p_{1}^{\frac{m-1}{m}}-p^{\frac{m-1}{m}}\right) \\
& \left\{1-\frac{\lambda}{\overline{\mathrm{R}}} p^{\frac{m-1}{m}} p_{1}^{\frac{1}{m}} v_{1}\right\}\left(1+\frac{\lambda \phi}{m \mathrm{R}}\right) \\
& =2 g \frac{m}{m-1} p_{1}^{\frac{1}{m}} v_{1}\left(p_{1}^{\frac{m-1}{m}}-p^{\frac{m-1}{m}}\right) \\
& \left\{1+\frac{\lambda}{\mathrm{R}}\left(\frac{\phi}{2 m}-\frac{p^{\frac{m-1}{m}} p_{1}^{\frac{1}{m}} v_{1}}{m}\right)\right\} \quad \text { to a first } \\
& =2 g \frac{m}{m-1} p^{\frac{1}{m}} v_{1}\left(p_{1}^{\cdot \frac{m-1}{m}}-p^{\frac{m-1}{m}}\right) \\
& \left\{1+\frac{\lambda p_{1} \frac{1}{m} v^{1}}{2 m \mathrm{R}}\left(p_{1}^{\frac{m-1}{m}}-p^{\frac{m-1}{m}}\right)\right\} \\
& =2 g \frac{m}{m-1} p_{1} v_{1}\left\{1-x^{m-1}\right\}\left\{1+\frac{\lambda \mathrm{T}_{1}}{2 m}\left(1-x^{\frac{m-1}{m}}\right) .\right\} \text {. } \\
& \therefore u^{2}=u_{c}^{2}\left\{1+\frac{\lambda \mathrm{T}_{1}}{2 m}\left(1-x^{\frac{m-1}{m}}\right)\right\} \text { to a first approximation, } \\
& \text { i.e. } u=u_{o}\left\{1+\frac{\lambda \mathrm{T}_{1}}{4 m}\left(1-x^{\frac{m-1}{m}}\right)\right\} . \quad . . . .
\end{aligned}
$$


592 Effect of Variable Spscific Heat on Gus Discharges.

But $\mathrm{Q}^{2}=\frac{A^{2} u^{2}}{v^{2}}$ and $\boldsymbol{v}^{2}=\frac{t^{2} v_{1}^{2}}{x^{\frac{2}{m}}}$ from (5).

$\therefore \quad Q^{2}=2 g \frac{m}{m-1} A^{2} \frac{p_{1}}{v_{1}}\left\{x^{\frac{2}{m}}-x^{\frac{m+1}{m}}\right\}$

$\left\{1-\frac{3 \lambda \mathrm{T}_{1}}{2}\left(1-x^{\frac{m-1}{m}}\right)\right\} \begin{gathered}\text { to a first } \\ \text { approximation. }\end{gathered}$

$\therefore \quad \mathrm{Q}=\mathrm{Q}_{c}\left\{1-\frac{3 \lambda \mathrm{T}_{1}}{4}\left(1-x^{\frac{m-1}{m}}\right)\right\}$.

If, however, $\quad \mathrm{K}_{p}=\mathrm{A}+\mathrm{ST}+\mathrm{S}^{\prime} \mathrm{T}^{2}$

and $\quad \mathrm{K}_{v}=\mathrm{B}+\mathrm{ST}+\mathrm{S}^{\prime} \mathrm{T}^{2}$

with $\lambda^{\prime}=\frac{\mathbf{S}^{\prime}}{\mathrm{B}^{\prime}}$,

then the formulæ (6) and (7) become respectively

and

$$
\begin{aligned}
& u=u_{c}\left\{1+\left(\lambda \mathrm{T}_{1}+\frac{\lambda^{\prime} \mathrm{T}^{2}}{2}\right)\left(\frac{1-x^{\frac{m-1}{m}}}{4 m}\right)\right\}, \ldots \\
& \mathrm{Q}=\mathrm{Q}_{c}\left\{1-3\left(\lambda \mathrm{T}_{1}+\frac{\lambda^{\prime} \mathrm{T}^{2}}{2}\right)\left(\frac{1-x^{\frac{m-1}{m}}}{4 m}\right)\right\} \ldots .
\end{aligned}
$$

It will be observed from formulæ (6) to (9) that, when $\mathrm{S}$ (or what is the same thing, $\lambda$ ) is positive, the velocity $u$ is greater under variable than under constant specific heat conditions, while $Q$, the quantity discharged, is less. The same applies, of course, to $\mathbb{S}^{\prime}$ and $\lambda^{\prime}$. If $\lambda$ and $\lambda^{\prime}$ are negative, then the velocity $u$ is less and the discharge $Q$ is greater than under constant specific heat conditions.

- 'The foregoing analysis suggests another method of specific heat determination, besides those alrealy in use. By the provision of a suitably short convergent nozzle of invariable coefficient of contraction under all conditions, the application of equations (6) to (9) to the discharges obtained would enable the values of $\lambda$ and $\lambda^{\prime}$ to be derived. This method has, at least, decided advantages over most others, particularly in the simplicity both of the experimental work and calculations involved.

It is to be observed, of course, that the same qualification must be applied to these variable specific heat equations (6) to (9) as are applied to the usual constant specific heat formulæ. That is, they must be used as they stand, only for cases of flow in which the discharge pressure is above or equal to the critical pressure, i.e., when the stream velocity at 
discharge is less than or equal to that of the velocity of sound through the gas under the discharge conditions which prevail. For discharge pressures below this value, the assumption (which is found to accord closely with experimental fact) is made that the maximum discharge value holds for all values of $x$.

Other points worth noting are:-

1. That the percentage error involved in the computation of discharges is three times the percentage error in velocity computations on a constant specific heat basis.

2. That the discharge error increases as $x$ decreases while the velocity error also increases.

3 . That the error in both velocity and discharge computations on a constant specific heat basis increases as the temperature of the gas in the reservoir is increased. In other words, for a given reservoir pressure $p_{1}$ the errors increase as the density of the gas in the reservoir is diminished.

The conclusions reached here with regard to the effect of variable specific heat on gas discharges are somewhat like those reached in a previous paper* by the writer on "The Effect of Variable Specific Heat on Thermodynamic Cycle Efficiencies." The equations deduced in that paper were of analogous form to those given here for orifice discharges. The applicability of the former to, and their value in, practical internal conbustion work has since been fully demonstrated, and it is hoped that equations (6) to (9) may prove of equal value.

LXX. The Motion of Electrons in Argon. By J. S. TownsEnd, M.A., F.R.S., Wykeham Professor of Physics, Oxford, and V. A. BaILey, M.A., Queen's College, Oxford $\dagger$.

1. IN the December number of the Philosophical Margazine 1 we gave an account of the motion of electrons in nitrogen, hydrogen, and oxygen, and it was shown that the loss of energy of an electron in colliding with a molecule, and the mean free path of the electron, may be found from the experimental determinations of the velocity of the electron in the direction of the electric force and its velocity of agitation. We give in this paper the results of similar

* Phil. Mag. Sept. 1917.

$\dagger$ Communicated by the Authors.

Phil. Mag. S. 5. Vol. 43. No. 255. March 1922. 2 Q 